\title{
La disolución jurisprudencial del requisito legal "sin previo contrato" de la acción de precario, primera parte
}

\author{
doi: 10.33264/rpa.202101-10 \\ Fernando Ruiz Astete \\ Facultad de Humanidades y Ciencias Sociales \\ Escuela de Derecho
}

\section{Resumen}

La acción de precario consagrada en nuestro Código Civil emana de una norma muy breve que ha debido ser interpretada por la jurisprudencia de nuestros tribunales para dotarla de contenido. Para ello, las sentencias de la Corte Suprema han fijado criterios para entender cuando se está ante un "previo contrato", criterios que se han alejado de su definición, fijada en el art. 1438. Se vuelve entonces necesario desentrañar cuales son los factores que han llevado a la Corte a entender que se está ante un "contrato" y en que casos no, a fin de permitir anticipar los futuros criterios de rechazo o aceptación de los recursos de casación en el fondo que permanentemente se están incoando en sus estrados en esta materia. Para ello se analizan fallos de la Corte Suprema en recursos de casación en el fondo durante un periodo de diez años.

Palabras clave: acción de precario, previo contrato, artículo 1438, posesión, carga de la prueba, título de dominio.

\begin{abstract}
The precarious law enshrined in our Civil Code emanates from a very short rule that must have been interpreted by the jurisprudence of our courts to give it content. For this, the justices of the Supreme Court have set criteria to understand when facing a "prior contract", criteria that have departed from its definition, set in art. 1438. It then becomes necessary to unravel what are the factors that have led the Court to understand that there is a "contract" and in which cases not, to allow anticipating the future criteria of rejection or acceptance of appeals. Deep down that they are constantly beginning their footsteps in this matter. For this purpose, Supreme Court rulings in appeals are analyzed in the merits over a period of ten years.
\end{abstract}

Keywords: precarious tort - prior contract - article 1438 - Chilean civil code - Chilean private law - possession - burden of proof - domain title 


\section{1.- La norma del artículo 2195, Inc. $2^{\circ}$ y el requisito negativo para la procedencia de la acción: No existencia de un contrato previo.}

La doctrina chilena y la jurisprudencia de los tribunales han reconocido y construido la llamada acción de precario a partir del inc. $2^{\circ}$ del art. 2195 del Código Civil, adquiriendo esta norma gran relevancia debido al elevado número de causas que se ventilan en los tribunales como producto del ejercicio de esta acción. Sólo la Corte Suprema dicta un promedio de dieciséis sentencias al año. Ello sin mencionar el gran numero de causas que nunca llegaron a ese tribunal desde los tribunales de la instancia.

Aun cuando aparenta ser sencilla, la norma mencionada ha suscitado muchas dificultades prácticas. Primero, porque, aunque está inserta dentro de la regulación del contrato de comodato, la acción que ahí se consagra no deriva de una hipótesis de tal convención. En seguida, porque la norma discurre sobre la base de que no exista un contrato que vincule jurídicamente a las partes y que le dé derecho al demandado a detentar la cosa (sólo así podría tener éxito la acción y el dueño recuperará la tenencia de la cosa); finalmente, la Corte Suprema ha sido muchas veces contradictoria respecto del modo en que se deben entender en cada caso los requisitos clásicos de la acción, que ella misma ha construido a partir de la norma ${ }^{16}$. A pesar de estas circunstancias, la doctrina ${ }^{17}$ al respecto no es tan nutrida como la jurisprudencia que se estudiará.

Cobra entonces por ello especial importancia el estudio jurisprudencial de los requisitos doctrinarios y legales de esta acción por cuanto en muchas ocasiones debe dilucidarse si es ella la que corresponde ejercer o deben preferirse otras, emanadas de contratos tales como el de arrendamiento o el de comodato. De ser así, el pretensor verá rechazada la acción de precario por no ser la idónea para el caso, sin que esto signifique que el tribunal le esté negando la calidad de dueño.

Por la extensión del tema, desarrollaremos este análisis en dos artículos, de los cuales éste es el primero que ve la luz, mediante un análisis dogmático jurisprudencial ${ }^{18}$,

\footnotetext{
${ }^{16}$ V. Gr. Bautista y otro con Mora y otro, 5545-2014, 8 CL/JUR/9444/2014. “Así entonces, el demandado podría enervar la acción, sea probando que el demandante no es dueño del bien objeto de la litis; sea negando que ocupe tal bien o, finalmente, alegando la existencia de un previo contrato que justifica su tenencia y/o, que en los hechos no existe ignorancia o mera tolerancia del dueño respecto de tal tenencia. Por su parte, el demandante intentará negarle a tal previo contrato o título toda capacidad para detener su acción".

17 Podemos mencionar especialmente a: RAmos Pazos, René. "Del Precario", Revista de Derecho Universidad de Concepción, $n^{\circ}$ 180, año LIV (Jul-Dic, 1986), Concepción. Citado textualmente en Gallo con Pinto, 3493-2012, $5^{\circ}$, CLJJUR/594/2013; y en olivares y otros con vera, 11835-2011, 5, 14/01/2013, CLIJUR/90/2013; HALABÍ RIFFO, Fuad; SAFFIRIO SUÁREZ, Carlos, La acción de precario ante la doctrina y la jurisprudencia, Editorial Jurídica Conosur, Santiago, 1996; ROSTION CASAS, Ignacio, El precario en la jurisprudencia chilena (1996 a 2013), Legal Publishing- Thomson Reuters, Santiago, 2014.

${ }^{18}$ Centraremos éste trabajo en la jurisprudencia recaída en el inc. 2 del art. 2195, y principalmente en la emanada de la Corte Suprema entre los años 2005 y 2015 que se hayan referido al requisito "sin previo contrato". A menos que se diga otra cosa, Revista Pensamiento Académico de la Universidad UNIACC
} 
apuntando especialmente al requisito "sin previo contrato" que establece el art. 2195, inc. $2^{\circ}$ del Código Civil, examinando el significado que la Corte Suprema le ha dado.

En este primer artículo mostraremos que el concepto de "previo contrato" que usa la norma ha sido claramente superado por la jurisprudencia y vaciado por ella del contenido normativo que mandata el art. 1438 extendiéndose a figuras que no constituyen contrato, pero que crean, en opinión de la Corte, un "vinculo jurídico" que justifica la tenencia del bien objeto de la acción, siempre y cuando se justifique una detentación material. Veremos también que la falta de inscripción en el Conservador de Bienes Raíces del título invocado no impide que este sea considerado previo contrato. La existencia de otras acciones disponibles para el demandante que obstan al éxito de la acción de precario por lo que ésta se transforma en una última alternativa que sólo puede usarse en ausencia de otras más idóneas.

En un segundo artículo estudiaremos el requisito de la ignorancia o mera tolerancia, la mencionaremos especialmente en cuanto de la jurisprudencia estudiada parece desprenderse que se encuentran íntimamente unidas, con el "previo contrato" al punto que parecen constituir un solo todo. Observaremos que, en ocasiones, cuando efectivamente se alega un previo contrato, puede ocurrir que no hayan sido parte en él el demandante o el demandado o ninguno de ellos, por lo que será necesario dilucidar los criterios que la Corte utiliza para vincular o no jurídicamente a las partes. Examinaremos sentencias en que se estimó que la posesión no era asimilable al concepto de previo contrato. Finalmente, nos ocuparemos del problema de la carga de la prueba.

\section{2.- Naturaleza Jurídica del "Previo contrato"}

Para desarrollar este análisis, hemos reunido sentencias de la Corte Suprema bajo diversos epígrafes descriptivos, buscando encontrar el marco común que las agrupa, más allá del previo contrato o título específico que se haya invocado en cada caso. Creemos que de esta manera se puede lograr una mayor comprensión de las tendencias jurisprudenciales que se describirán.

Pero antes debemos aclarar que el texto del artículo 2195, inc. $2^{\circ}$ exige que no exista "previo contrato" para que proceda la acción, pero como la jurisprudencia le ha dado a éste un significado muy amplio, en adelante hablaremos indistintamente también de "título justificante", "título previo", "apoyo o título jurídicamente relevante" u

toda sentencia citada deberá entenderse emanada de ese tribunal. Hemos recopilado para ello las sentencias disponibles en la base de datos en línea de Legal Publishing - Thomson Reuters, incluyendo en cada caso el código de identificación utilizado por esa base de datos para facilitar su posterior búsqueda por el lector. 
otros términos que la jurisprudencia utilice.

\section{3.- Justificación de la tenencia: Un vínculo jurídico equivale a la existencia de un previo contrato}

1. Para que la defensa sea exitosa, se debe probar que existe una justificación para la tenencia que se ejerce. Esta justificación debe estar constituida por un vínculo jurídico que una a ambas partes. A su vez, este vínculo jurídico debe nacer de un "previo contrato", alegato que es usado por la mayoría de las defensas de los precaristas, que se centran precisamente en demostrar su existencia para justificar la tenencia y pedir el rechazo de la acción ${ }^{19}$.

Así, la jurisprudencia afirma que basta que asista al tenedor cualquier clase de justificación para la ocupación que lleva a cabo, para desvanecer el precario ${ }^{20}$. De esto se infiere que la acción de precario es la última opción que puede tomar el demandante para obtener la restitución del bien, utilizable sólo en caso de que carezca de otra acción viable, ya que si existe cualquier vínculo jurídico que justifique la tenencia, la acción debe rechazarse ${ }^{21}$.

2. A este respecto podemos preguntarnos cómo se puede establecer la existencia de tal vínculo jurídico o, en otras palabras, cuando existe un título jurídicamente relevante.

Podríamos utilizar como indicador la participación en tal título del demandante, propietario del bien. Sin embargo, la jurisprudencia ha dicho que el título que justifica la tenencia no necesariamente debe provenir del propietario del bien (tema que se trata en otro acápite de este trabajo), sino que lo relevante radicará en que el derecho que emana del referido título o contrato que legítima esa tenencia, pueda ejercerse

\footnotetext{
19 También, aunque en una minoría de casos se constató la utilización como defensa de la afirmación de que el demandante no era dueño de la cosa. Estos últimos casos quedarán fuera de este trabajo, pero se mencionarán por la relación que tienen con el alegato de posesión de algunos precaristas. V. Gr. Barraza y otros con Fisco de Chile, 7849-2013, $7^{\circ}, \mathrm{CL} / \mathrm{JUR} / 2391 / 2013$. En este fallo se confunde el requisito sin previo contrato, con el requisito del dominio del demandante. En efecto, la Corte Suprema afirmó que la concesión de explotación minera, alegada como previo contrato por la demandada, no permite ocupar el predio superficial, por lo que "mal podría entenderse que la existencia de la ya referida concesión minera pueda servir de título suficiente para justificar la ocupación del terreno sub lite por parte del demandado antes individualizado, la que sólo encuentra explicación en la ignorancia o mera tolerancia de su dueño". En los hechos descritos, en realidad la demandada intentó usar, como previo contrato justificante de su tenencia, el dominio de un bien diferente, la concesión de explotación minera "pertenencia que constituye un derecho real e inmueble distinto e independiente del dominio del predio superficial por así disponerlo expresamente el Código de Minería en su artículo $2^{\circ}$ ". Sin embargo la Corte al parecer no lo ve así, asumiendo que es un título pero que no es oponible al demandante, cuando en realidad se trata de un caso de ausencia de título justificante.

20 Serón con Soza, 3158-2013, 14, CL/JUR/1921/2013.

${ }^{21}$ V. gr. Servicios gráficos con Inversiones e Inmobiliaria, 13741-2013, 6 , De la Sotta con Arriagada, 7472-2013, 5, $\mathrm{CL} / \mathrm{JUR} / 2901-$ 2013. Desde el punto de vista del demandante, la jurisprudencia examinada afirma que es inherente al precario que esté constituido por una simple situación de hecho, la absoluta y total ausencia de todo vínculo jurídico entre el dueño y el tenedor de la cosa, esto es, una tenencia meramente sufrida, permitida, tolerada, o ignorada, sin fundamento, apoyo o título jurídicamente relevante
} 
respecto del propietario, sea porque él o sus antecesores contrajeron la obligación de respetarla -si el derecho del tenedor u ocupante es de naturaleza personal- o porque puede ejercerse sin respecto a determinada persona, si se trata de un derecho real $^{22}$. En otras palabras, lo relevante es que exista vínculo jurídico entre demandante y precarista y éste puede existir aun cuando en el título del que emana no haya sido parte el actual dueño demandante.

3. Respecto al criterio con que ha enfrentado la Corte Suprema la construcción del vínculo jurídico, podemos ejemplificar con dos casos. En ellos existía contrato de compraventa previo entre las partes del juicio y en ambos casos con incumplimiento de entrega material de la cosa vendida. Sin embargo, las soluciones fueron diametralmente opuestas.

a.- En un caso la Corte Suprema afirmó la existencia del vínculo jurídico que justificaba la tenencia, aclarando que la vía idónea que tiene el demandante comprador del bien inmueble, que no ha logrado la entrega material, es otra distinta de la acción de precario. En este caso el demandado vendedor invocó el contrato de compraventa como título justificante, a pesar de que no había entregado materialmente el inmueble. La Corte estimó que le servía de título ese mismo contrato y que le era oponible al demandante comprador, dueño inscrito ${ }^{23}$.

b.- Sin embargo, en otro caso, negó la existencia de tal vínculo, a pesar de que se trataba de situaciones análogas. En efecto, era un caso de compraventa forzada en pública subasta, en que el tribunal afirmó "en lo que atañe a la alegación del demandado en cuanto a que la adjudicación en pública subasta del inmueble de autos desvirtuaría la inexistencia de un vínculo entre actor y demandado, cabe señalar, sin perjuicio de tratarse de una compraventa con características particulares, que dicho acto sólo acredita que el demandado dejó de ser dueño del inmueble aludido y que lo ocupa actualmente sin título y por mera tolerancia del actual propietario $24 " 25$. Como puede observarse, en este caso, a diferencia del anterior, el tribunal estimó que el contrato de compraventa no era título suficiente para formar el vínculo, por lo que desechó las alegaciones de la precarista.

\footnotetext{
${ }^{22}$ Castro Cruz Cristian con Fisco de Chile y otros, 5457-2013ㅇ, CL/JUR/482/2014.; Puga con Contreras, 12256-2013, CL/JUR/150/2014. ${ }_{23}^{23}$ Serón con Soza, 3158-2013, 13ㅇ, CL/JUR/1921/2013: “DÉCIMO TERCERO: Que, en el caso que nos convoca, el vendedor satisfizo parcialmente su obligación de entrega, pues proporcionó la legal, que se realizó mediante la correspondiente inscripción del contrato de compraventa, pero no la material, obligación que es igualmente exigible al vendedor, mas no por la presente vía, quedando, en todo caso, a salvo otros derechos para el actor En consecuencia y para efectos de resolver la acción de precario deducida en autos, corresponde concluir que el título esgrimido reúne las características a que se ha hecho mención precedentemente, por cuanto el ordenamiento le reconoce la virtud de vincular jurídicamente al tenedor con el predio, de forma tal de situar a su propietario en posición de tener que respetar esa tenencia. Dicho de otro modo, el título empleado resulta oponible al demandante dueño inscrito del inmueble, esto es, le empece, de forma tal que se encuentra en el imperativo de tolerar la ocupación".

24 Énfasis añadido.

25 Escobar con Faundez, 16675-2013, 15 , CL/JUR/2930/2014. 
Al parecer la diferencia fundamental está en la circunstancia de que se trataba de una compraventa voluntaria la primera y forzada la segunda. Creemos que en este segundo caso se negó la existencia de un vínculo jurídico justificante con el fin de asegurar la certeza jurídica de las compraventas realizadas mediante remate judicial.

4. También podemos encontrarnos en situaciones en que ninguna de las partes del juicio concurrió a la celebración del contrato previo invocado por la demandada, pero en los que se entiende que existe el vínculo jurídico. Así, en un caso la cónyuge del demandado compró el $50 \%$ de los derechos sobre un inmueble, pero esta compraventa se llevó a cabo ante un Oficial del Registro Civil, quien actuó "en sus funciones de Notario" 26 . Este documento no era escritura pública y no se inscribió en el registro conservatorio correspondiente. El demandante adquirió posteriormente el dominio del inmueble y demandó de precario, no a la promitente compradora, sino al cónyuge de ésta, quien en los hechos la detentaba. La Corte favoreció a la demandada para lo cual tuvo que extender su raciocinio en dos frentes: primero, le dio el valor de vínculo jurídico justificante de la tenencia a un contrato de compraventa que no cumplía con los requisitos de legales de escritura pública, estimando que sí cumplía las exigencias de la norma del art. 2195, inc. 2 del Código Civil. Así, expresó textualmente que "entre doña María Guillermina Contreras Fuentealba y doña María Angélica Navarro Quilodrán existió un vínculo de carácter contractual, en que la primera tenía la calidad de vendedora y, la segunda, la de compradora" 27 . En segundo lugar, extendió los efectos de este contrato al cónyuge de la compradora, cónyuge que no fue parte del contrato que usa para justificar su tenencia. Lamentablemente, la Corte no da ningún argumento para justificar tal extensión, rechazando la casación y limitándose a declarar que "el demandado no ocupa el bien por la mera tolerancia, simple condescendencia o aceptación del dueño del mismo, sino que en virtud de un contrato de compraventa en que era parte su cónyuge, extendiéndose los efectos del mismo a don Fernando Contreras Fuentealba, pese a no haber concurrido personal y directamente a su celebración" 28 .

\section{4.- El previo contrato se puede extender a figuras que jurídicamente no son contratos}

1. La Corte Suprema se ha pronunciado respecto del problema de establecer la extensión que se le debe dar a la voz “contrato" del art. 2195, i. 2, ya sea restringiéndola a la definición legal que nos entrega el art. 1438 o extendiéndola a figuras distintas que justifiquen un vínculo jurídico que demandante debe respetar,

\footnotetext{
${ }^{26}$ Puga con Contreras, 12256-2013, $7^{\circ}$, CL/JUR/150/2014.

27 Puga con Contreras, $12256-2013,7^{\circ}$ y $8^{\circ}$, CL/JUR/150/2014.

${ }_{28}$ Puga con Contreras, 12256-2013, $9^{\circ}, \mathrm{CL} / J U R / 150 / 2014$. 
enervando la acción ${ }^{29}$. El tribunal se ha decantado por una interpretación amplia, que va más allá del significado que le da el mencionado art. 1438, incluso haciendo sinónimos "contrato" y "título justo"30.

Así, observamos que figuras jurídicas que no son de origen convencional o contractual han sido utilizadas como defensa por los demandados como la posesión, un testamento o decretos leyes ${ }^{31}$.

En este sentido, una sentencia expresa que "Por su parte, la expresión contrato ha sido definida por el legislador en el artículo 1438 del Código Civil, como el acto por el cual una parte se obliga para con otra a dar, hacer o no hacer alguna cosa. Si bien este es el concepto legal, la voz que utiliza el inciso $2^{\circ}$ del artículo 2195 citado se ha entendido en términos más amplios..." 32 .

En esta línea, la Corte Suprema afirma que basta, que asista al tenedor alguna clase de justificación para la ocupación que lleva a cabo para desvanecer el precario propiamente tal33, "aun cuando no sea de origen convencional o contractual" 34.

2. Al respecto, un fallo reciente estableció que "parece más acorde con el sentido de la figura en análisis, entender que la exigencia de un contrato previo alude a un título que justifique la tenencia más que a la existencia de una convención entre las partes, como quiera que, en ese caso, la situación contractual se aleja de la cuestión fáctica planteada en la norma del inciso segundo del artículo 2195 del Código Civil”35.

Este criterio se reafirma en un fallo que estimó que "se ha tenido por bastante para justificar la tenencia del predio por parte de la demandada, el convenio celebrado entre el Ministerio de Educación Pública y la Ilustre Municipalidad de Buin, con fecha 9 de marzo de 1982, por el cual, en cumplimiento de lo dispuesto en el artículo 38 del D.L. 30631979 y en el D.F.L. 1-3063 de 1980, se autorizó el traspaso de los establecimientos educaciones públicos, a las municipalidades. Aunque a la fecha del traspaso, la propiedad del establecimiento pertenecía al Servicio Agrícola y Ganadero, en virtud de lo dispuesto en el artículo $4^{\circ}$ del D.F.L. 278 de 1979 del Ministerio de Agricultura, no puede haber duda de la calidad de dominio público que

\footnotetext{
29 De La Maza Gazmurı, Íñigo, “Contratos especiales”, Revista Chilena de Derecho Privado, N 14 [julio 2010 ], pág. 179.

30 De la Sotta con Araneda, 7472-2013, $7^{\circ}$, CL/JUR/2901/2013: "Que en el caso en estudio la controversia se ha centrado en determinar si el tercer supuesto referido en el motivo anterior se ha verificado, o si, por el contrario, como lo plantea el demandado éste no se cumple. En efecto, constituyen hechos inamovibles del proceso aquellos determinados en relación con los dos primeros presupuestos de procedencia de la acción deducida, según se anotó en el razonamiento quinto que antecede, correspondiendo, entonces, dilucidar si la sentencia impugnada aplicó correctamente el derecho en cuanto estimó que la parte demandada detenta un título justo que permite la ocupación del predio". Énfasis añadido.

${ }^{31}$ V. Gr. Rodríguez con Valdebenito, 8489-2013, CL/JUR/2933/2014.

${ }^{32}$ Puga con Contreras, 12256-2013, 6 , CL/JUR/150/2014. Énfasis añadido.

33 Soto con Bustamante y otro, 2489-2012, $13^{\circ}, \mathrm{CL} / \mathrm{JUR} / 642 / 2013$.

34 Suazo con Hume, 4095-2005, $5^{\circ}$, CL/JUR/5719/2007.

35 Salinas con Salinas, 5550-2014, $5^{\circ}$, CL/JUR/25/2015. 
a la sazón ella tenía" ${ }^{36}$.

De esta manera, un convenio celebrado entre dos terceros ajenos al dominio -una municipalidad y un Ministerio, que no era propietario, ya que a esa época lo era el Servicio Agrícola y Ganadero - sirve de título o contrato previo suficiente para justificar la ocupación del precarista demandado ya que la Corte estima que se trata de "dominio público" al ser todas estas entidades de carácter público.

Un aspecto interesante de este fallo es que el tribunal menciona expresamente que el inmueble estaba destinado al funcionamiento de un colegio municipal. Agrega como conclusión que la suma de ambos elementos -convenio basado en cuerpos legales y el uso efectivo del bien para el fin original tenido en vista- permite "afirmar que la demandada sí tiene título para usar el inmueble y que éste fue recibido con una precisa finalidad, prestar servicio de educación general básica, por lo que no se da el presupuesto que exige el artículo 2195 del Código Civil para estimar que se trata del uso de un predio atribuido a ignorancia o mera tolerancia del dueño". Es decir, estima que la finalidad y uso actual del inmueble, coincidente con aquel a que se le destinó por el título, permite excluir la mera tolerancia o ignorancia.

3. En otro caso, la Corte Suprema acogió un recurso de casación en el fondo en favor del precarista debido a que el título invocado por éste se estimó suficiente para enervar la acción a pesar de no ser un contrato, siendo más bien una institución de derecho de familia. En efecto, el precarista, padre de los demandantes "fue hasta el fallecimiento de su cónyuge el administrador del inmueble por el carácter que éste tenía de bien propio de la mujer, sin perjuicio que, como relatan los propios demandantes, la ocupación del mismo se origina en que el demandado vivió allí junto a su mujer e hijos los demandantes desde que se casó, en compañía de quienes a esa fecha eran los dueños de la propiedad" 37. Es decir, la calidad de marido administrador de un bien propio, adquirido en virtud de herencia por su mujer, parece título suficiente.

Sin embargo, se agregaron a ello otras circunstancias. El inmueble fue vendido por la cónyuge a sus hijos y, posteriormente, la muerte de ésta disolvió la sociedad conyugal sin que la comunidad resultante fuese liquidada. La Corte razona en su considerando $7^{\circ}$ diciendo que la cuestión "es un asunto de familia", agregando que "la situación descrita da cuenta de un conflicto jurídico que, en opinión de esta Corte, no procede resolver por la vía del precario". El fallo incluso describe otras acciones que podrían utilizarse para resolver la cuestión meramente patrimonial, tales como la autorización para enajenar del art. 138 bis en relación al art. 1754 del Código Civil. Afirma que su

\footnotetext{
${ }^{36}$ Farías con Corporación de Desarrollo Social de Buin, 3675-2012, 10², CL/JUR/1378-2013.

37 Salinas con Salinas, 5550-2014, 6 $6^{\circ}$ CL/JUR/25/2015. 
uso habría evitado la acción de precario y la demanda de nulidad de la compraventa del inmueble que entabló el padre demandado contra sus hijos. Finalmente, afirma que "la paz social, fin último del derecho, no parece alcanzarse si se canaliza la controversia por la vía intentada, cuyas connotaciones superan lo meramente patrimonial".

Ahora bien, es obvio que la muerte del cónyuge puso fin a la sociedad conyugal, por lo que la administración del marido cesó en ese mismo instante. Pero también parece claro que para la Corte en el considerando $1^{\circ}$ que "no se configura un precario por la circunstancia de que ese contrato se haya extinguido o perdido con posterioridad su validez o fuerza obligatoria". Al afirmarlo reproduce un argumento de la recurrente, pero el resultado del recurso parece confirmar que lo hace suyo.

3. En otra situación de derecho de familia resuelta por la Corte Suprema, ex cónyuges divorciados litigaron de precario pues uno de ellos habitaba un bien raíz adquirido durante la vigencia de la sociedad conyugal. La cónyuge demandante de precario alegó que éste fue adquirido por ella, que se divorció renunciando a las gananciales y que, además, el bien fue adquirido mediante subsidio habitacional, de modo tal que en la compraventa ella debía ser considerada separada de bienes por mandato legal. La sentencia de primera instancia, a pesar de estos antecedentes, rechazó la demanda al considerar que "que la sola circunstancia de que el demandado pudiese ser titular de derechos derivados de las relaciones de familia que lo habilitaren para detentar la ocupación del bien, enerva los supuestos exigidos por el artículo 2195 del Código Civil, en orden a la tenencia por mera tolerancia del bien, careciendo de título"38.

La Corte, ratificando el fallo de segunda instancia que había favorecido a la demandada, expresó que "se acreditó que entre las partes existió vínculo matrimonial bajo el régimen de sociedad conyugal; que el bien fue adquirido durante la vigencia del matrimonio el que terminó por divorcio el año 2010 y que el demandado habita dicho bien, de modo tal que -interpretando de modo amplio la referencia de "mero contrato" que invoca la norma- si puede estimarse que cuenta con antecedentes jurídico o causa que justifique su ocupación, de modo tal que no se encuentra en la situación de "precario" prevista por la ley" 39.

De esta manera, la combinación de estos antecedentes: matrimonio, adquisición del bien durante el matrimonio, divorcio y, finalmente, que el demandado habita dicho bien; configuran para la Corte un título que justifica la tenencia. No se hace cargo la Corte del hecho de que, por la circunstancia de haber sido adquirido el bien bajo

\footnotetext{
${ }^{38}$ Martínez con Peñailillo, 24273-2014, 2 , CL/JUR/8456/2014.

39 Martínez con Peñailillo, 24273-2014, 5, CL/JUR/8456/2014. 
subsidio habitacional, la ley consideraba a la mujer separada de bienes del marido. Estimamos que la sola circunstancia del matrimonio, a pesar del divorcio posterior, es en el fondo la justificación que la Corte asume para fallar en favor de la demandada, aun cuando ya no esté vigente.

4. Finalmente, se debe aclarar que el previo contrato invocado puede ser uno de comodato, sin embargo, en este caso, más que ante un previo contrato que justifica la tenencia del precarista, la acción será rechazada porque no es la adecuada para defender el derecho del demandante. En efecto, en esta situación lo que sucede es que el demandante deberá utilizar las acciones de restitución que emanan del contrato de comodato. Todo esto, en el entendido de que el demandante efectivamente dispone de estas acciones.

En todo caso, la Corte Suprema requiere que la existencia del comodato se pruebe. Así, una sentencia de casación en el fondo reproduce el considerando $8^{\circ}$ de la de primera instancia, expresando que la actora "no allegó antecedentes probatorios idóneos para acreditar lo expuesto en su contestación, en cuanto en forma coetánea a la venta del inmueble, se habría celebrado un contrato de comodato con la compradora (actualmente demandante), acordando como fecha de restitución de la propiedad de autos, el día 28 de mayo de $2015 "{ }^{40}$. De esta manera, la Corte refuerza lo que se había afirmado anteriormente, en orden a que el contrato de comodato excluye el precario, lo que no sucedió en este caso por falta de prueba ${ }^{41}$.

\section{5.- Basta con que el previo contrato sea oponible al verdadero dueño para enervar la acción, siempre que justifique la detentación material}

1. De la jurisprudencia estudiada se desprende que el previo contrato debe justificar la detentación material de la cosa. Pero a este necesario requisito se debe agregar la exigencia de que sea oponible al verdadero dueño.

Esta es una interpretación restrictiva de la exigencia, y así la jurisprudencia ha dicho “... y que ese título resulte oponible al propietario, de forma que la misma ley lo ponga en situación de tener que respetarlo y, como consecuencia de lo anterior, de tolerar o aceptar la ocupación de una cosa de que es dueño por otra persona..." ${ }^{42}$.

\footnotetext{
40 Zúñiga con Correa, 22612-2014, $3^{\circ}, \mathrm{CL} / J U R / 7715 / 2014$.

${ }^{41}$ Pero es de notar que la Corte no toma en cuenta que la demandada fue cónyuge del dueño anterior, es decir, que hay un vínculo jurídico entre el dueño anterior y ella que pudo haber utilizado para construir un título. Esta eventual construcción sería congruente con la jurisprudencia que ha aceptado que se esgriman como previo contrato vínculos jurídicos entre partes distintas a aquellas que son parte del procedimiento sumario de precario, es decir, con terceros: "el bien cuya restitución se persigue era de propiedad de su cónyuge -del cual se encuentra separada de hecho- el que lo enajenó a la demandante la que le debía entregar el bien en comodato a su parte por el plazo de 3 años contados desde la celebración de la compraventa”, Zúñiga con Correa, 22612-2014, $2^{\circ}$, CL/JUR/7715/2014.
}

42 Puga con Contreras, 12256-2013, 6 CL/JUR/150/2014; Díaz con Torres, 1730-2014, $7^{\circ}$, CL/JUR/5268/2014. También, Servicios con Inversiones, 13741-2013, 6 , CL/JUR/82/2014: "Para que el título invocado sea oponible al dueño debe ocurrir que la misma ley ponga al propietario en situación de respetarlo y, como consecuencia de lo anterior, de tolerar o aceptar la ocupación de una Revista Pensamiento Académico de la Universidad UNIACC 
Así, existe tal oponibilidad en el caso de un contrato de promesa de compraventa celebrado entre el ocupante del bien y el antecesor en el dominio del inmueble. Según una sentencia ${ }^{43}$, tal contrato servirá como justificación suficiente de la detentación, pues existió pago de una parte del precio de la futura compraventa y la entrega material del inmueble por parte del promitente vendedor.

En todo caso, en este fallo el tribunal cae en el error de confundir el contrato de promesa con el contrato de comodato. Es de resaltar, además, que el representante legal de la persona jurídica demandante era, a su vez, la persona natural que prometió vender a la demandada, por lo que, afirma la Corte Suprema transcribiendo parte del fallo de segunda instancia: “la ocupación por parte del demandado encuentra su fundamento en la entrega que el propio representante legal de la demandante, y antecesor en el dominio del inmueble realizara con fecha diez de diciembre del año dos mil diez, en virtud de un contrato de promesa de compraventa sobre los inmuebles cuya restitución solicita, en términos que no es posible sostener que tal ocupación no lo sea sin previo contrato y por mera tolerancia o ignorancia del demandante" 44.

En otro caso también se estimó que el título era oponible al verdadero dueño: la Corte Suprema debió dilucidar si la calidad de accionista de una sociedad anónima era suficiente título para enervar la acción deducida por la misma sociedad contra uno de sus socios, concluyendo que sí era posible. En los hechos, tres comuneros le vendieron sus derechos hereditarios a una sociedad anónima. En esta persona jurídica esos mismos tres comuneros cedentes eran accionistas con un cuarto socio. Este socio fue demandado de precario por la sociedad. La acción no tuvo éxito, pues el tribunal estableció que la calidad de accionista de la sociedad propietaria del inmueble era título oponible al demandante, que era la misma sociedad: "la ocupación está amparada en un título oponible al demandante, consistente en la calidad de accionista de dicha sociedad" 45. 
2. En otro caso se esgrimió como previo contrato un testamento. Pero en esta situación no era oponible al dueño ya que, si el testamento esgrimido favorece a una tercera persona distinta del ocupante, ajena al juicio, no es justificación suficiente ${ }^{46}$. Recalca la sentencia citada que la circunstancia de que el actual ocupante sea heredero de la persona fallecida y beneficiada en el testamento con el bien ocupado no es suficiente sí el testador estableció que, a la muerte del beneficiado, el inmueble pasara a un tercero distinto del ocupante actual. En este caso, agrega, se trata de derechos personalísimos que, al ser intransmisibles, no le sirven de justificación a su heredero para detentar la cosa ${ }^{47}$.

Podemos concluir entonces de los casos citados que sí el previo contrato no cumple el requisito de oponibilidad, se está ante la ausencia total de nexo jurídico, entre quien tiene o detenta la cosa y el dueño; o, entre quien tiene o detenta la cosa y la cosa misma, por lo que la acción devendría en exitosa.

\section{La inscripción del título en el Registro Conservatorio no es requisito de oponibilidad del previo contrato}

La Corte Suprema ha establecido que el previo contrato en que se constituye un derecho real sobre un inmueble no requiere, para ser oponible, la correspondiente tradición-inscripción en el registro conservatorio.

Será título válido un previo contrato no inscrito, ya que "el título esgrimido por los demandados, para justificar su ocupación, corresponde a un acto suscrito por esa parte y doña Elizabeth María Beck, antecesora en el dominio de la actora, mediante escritura pública de fecha 29 de junio de 2004, que da cuenta de la constitución de los derechos de uso y habitación a favor de doña María Eduvigis Klumpp Baumert, recaídos en el bien raíz materia del presente juicio; acto al cual la actora le resta validez por no haber sido inscrito, en su oportunidad, en el Conservador de Bienes Raíces respectivo. Respecto de este tópico, que ha servido de principal sustento al

Cuarto: Que, por ende, es necesario concluir que el recurso de casación en el fondo deducido debe ser desestimado por adolecer de manifiesta falta de fundamento, dado que al no concurrir los supuestos de la acción de precario consagrados en el inciso $2^{\circ}$ del artículo 2195 del Código Civil, no procedía que se hiciera lugar a la demanda intentada.

Por estas consideraciones y de conformidad, además, con lo dispuesto en el artículo 782 del Código de Procedimiento Civil, SE RECHAZA el recurso de casación en el fondo interpuesto en contra la sentencia de ocho de septiembre de dos mil catorce, escrita a fojas 212 y siguientes".

46 "es insuficiente para considerar que dicha parte goza de un título al cual el ordenamiento le reconoce la virtud de vincularlo jurídicamente con el predio, de forma tal de situar a su propietaria en posición de tener que respetar esa tenencia. En efecto, el acto unilateral esgrimido, a más de favorecer a una tercera persona, María Estrella Arriagada Cordero, ajena al juicio y actualmente fallecida, consigna, de manera expresa, que a la muerte de esta última, hecho que se ha verificado, es voluntad de la testadora que la propiedad "pase a la sociedad Ciego, Sordo y Mudos" (cláusula cuarta). De manera que no ha podido el demandado invocar en apoyo de su ocupación el testamento aludido ni tampoco la calidad de heredero de quien aparece beneficiada por el mismos. Consecuencialmente, la actora no se encuentra en el imperativo de tolerar la ocupación y, por ello, la ley la ampara en su derecho a rescatar la tenencia de la propiedad, a fin de ejercer en forma plena los atributos que reconoce el dominio;", De la Sotta con Araneda, 7472-2013, 9, CL/JUR/2901/2013.

47 De la Sotta con Araneda, 7472-2013, 11 ${ }^{\circ}, \mathrm{CL} / J U R / 2901 / 2013$. 
recurso en estudio, corresponde apuntar que la inscripción que extraña la demandante no configura una solemnidad exigible para la constitución del usufructo y, consecuencialmente, de los derechos de uso y habitación invocados, apareciendo, en cambio, que aquélla se erige como un acto posterior, y cuya omisión no resta validez al acto que ya nació. Cosa distinta es la tradición de aquellos derechos reales, que pueda concretarse más tarde." ${ }^{48}$.

Ratificando lo dicho, recientemente, la Corte Suprema afirmó respecto de un derecho real de usufructo no inscrito, usado como previo contrato por la demandada "que se impugna por el recurrente la validez del usufructo vitalicio al no haberse inscrito en el Conservador de Bienes Raíces respectivo la escritura pública y sus modificaciones posteriores. Sin embargo, y tal como se dijo en el motivo octavo, aquella omisión no obsta a la conclusión, conforme a la cual, para los fines previstos en el segundo inciso del artículo 2195 del Código Civil, se está frente a uno de aquellos contratos en tanto título que reúne los requisitos que el ordenamiento exige para vincular jurídicamente al tenedor con el predio, de forma tal de situar a su propietario en posición de tener que respetar esa tenencia. Dicho de otro modo, el título empleado sí resulta oponible al demandante dueño inscrito del inmueble, esto es, le empece, de forma tal que se encuentra en el imperativo de tolerar la ocupación"49.

\section{La posibilidad de invocar otras acciones emanadas de un previo contrato obsta a la acción de precario}

De la jurisprudencia estudiada se desprende que la existencia de acciones disponibles para el propietario demandante, distintas de la de precario, traen por consecuencia que la Corte estime que aquellas son las que se deben ejercer y no las que nos ocupa. Sin embargo, no siempre se desprende expresamente del fallo esta idea, como en el caso que pasamos a describir. En él, el demandante era sucesor en el dominio que detentaba el arrendador. Sin embargo, el contrato de arrendamiento se celebró después de haber cedido el dominio al actual propietario demandante ${ }^{50}$.

\footnotetext{
${ }^{48}$ Agroindustria con Klumpp y otro, 4018-2012, $19^{\circ}$, CL/JUR/2861/2013.

49 Robles con Terra, 819-2014, $10^{\circ}$, 20 de noviembre de 2015.

50 Tenis con Inmobiliaria, 8304-2012, $17^{\circ}, \mathrm{CL} / J U R / 1483 / 2013$. “Que, en el caso de autos, el título que no se tuvo por bastante por los jueces de la instancia para justificar la tenencia del predio por parte del demandado, corresponde a un contrato de arrendamiento celebrado mediante instrumento privado en el mes de febrero de 2010, entre este último e Inversiones Santa Paula S.A., quien a su vez, en el año 2003 transfirió la propiedad de los predios en cuestión a la sociedad demandante, y que a partir del año 2004 se encuentran inscritos en el Registro de Propiedad pertinente a nombre de la actora. Luego, este título no reúne las características a que se ha hecho mención, por cuanto el ordenamiento no le reconoce la virtud de vincular jurídicamente al tenedor con el propietario ni con el predio, de forma tal de situar a su dueño en posición de tener que respetar esa tenencia. Dicho de otro modo, el título esgrimido no resulta oponible al demandante dueño inscrito del inmueble, esto es, no le empece, de forma tal que no se encuentra en el imperativo de tolerar la ocupación y, por ello, la ley lo ampara en su derecho a rescatar la tenencia de la propiedad, a fin de ejercer en forma plena los atributos que reconoce al dominio, desde que no obstante conferir derechos e imponer obligaciones a los contratantes de la referida convención, quien aparece como arrendadora ningún derecho detentaba sobre los inmuebles, de manera que, sin minar la validez del contrato, ninguna exigibilidad tiene respecto del propietario, quien no concurrió a su celebración".
} 
Dice la Corte en este fallo que "el título esgrimido no resulta oponible al demandante dueño inscrito del inmueble", sin embargo, no explica porque razón es así. Creemos que la solución es correcta ya que nos encontramos ante un caso de arrendamiento de cosa ajena del art. 1916, i. $2^{\circ}$ que, aun siendo válido, resulta inoponible al propietario. Aquí no cuenta el propietario con la acción restitutoria por extinción del derecho del arrendador del art. $7, \mathrm{n}^{\circ} 4$ de la ley 18.101 ya que el arrendador nunca tuvo derecho alguno en el inmueble y, por ende, no podía éste extinguirse ${ }^{51}$. Al contrario de la situación descrita en el fallo, si el demandante fuese sucesor en el dominio de un bien arrendado por su antecesor cuando efectivamente le pertenecía a éste, entonces el sucesor debería ejercer tal acción restitutoria y ello excluiría la de precario. Creemos que aquí estamos en una situación en que, más que un contrato oponible en los términos del art. 2195, i. $2^{\circ}$, los tribunales han impedido un cúmulo o elección de acciones: sólo si no hay otra acción disponible, puede ejercerse la de precario.

\section{Conclusiones}

Finalizando esta primera parte de la investigación, podemos extraer, a modo de resumen, algunas conclusiones:

1.- El previo contrato que exige la norma del art. 2195 , i. $2^{\circ}$ puede no ser un contrato en los términos del art. 1437 del Código Civil, sino una figura jurídica diferente, tales como la posesión, un testamento o un convenio entre entes públicos.

2.- El previo contrato, para ser útil a la defensa del demandado debe constituir un vínculo jurídico que una a ambas partes.

3.- El vínculo jurídico, nacido del previo contrato, debe justificar la tenencia del demandado, para que la defensa sea exitosa.

5.- La acción de precario puede ejercerse sólo si el demandante carece de otras, por lo que a este respecto se debe excluir la posibilidad de elección o cúmulo de acciones. Lo relevante para saber si esta defensa es oponible estriba en la posibilidad que tiene el demandante para ejercer acciones emanadas de otros contratos, aun cuando no hayan sido celebrados con él como, por ejemplo, es el caso de las acciones del art. 1962 del Código Civil.

6. En los casos en que el previo contrato invocado constituya una institución de derecho de familia, como el matrimonio o la sociedad conyugal, la vía adecuada de solución al conflicto debe buscarse en las acciones que aquel provee y no en la acción de precario. Por ello estima previo contrato justificante de tenencia un matrimonio terminado por divorcio o una sociedad conyugal extinguida entre las partes.

7. Aun cuando el previo contrato alegado justifique la detentación material, no

${ }^{51}$ En el mismo sentido, ORREGO, Juan Andrés. Ponencia en XIII Jornadas de Derecho Civil, Facultad de Derecho, Universidad de
Concepción, 1 de octubre de 2015. Revista Pensamiento Académico de la Universidad UNIACC 
bastará con ello, sino que además debe serle oponible al demandante.

8. El previo contrato en que se constituye un derecho real sobre un inmueble no requiere, para ser oponible, la correspondiente tradición-inscripción en el registro conservatorio.

\section{Referencias}

DE LA MAZA GAZMURI, Íñigo, “Contratos especiales”, Revista Chilena de Derecho Privado, $\mathrm{N}^{\circ} 14$ [julio 2010].

HALABI RIFFO, Fuad; SAFFIRIO SUAREZ, Carlos, La acción de precario ante la doctrina y la jurisprudencia, Editorial Jurídica Conosur, Santiago, 1996.

ORREGO, Juan Andrés. Ponencia en XIII Jornadas de Derecho Civil, Facultad de Derecho, Universidad de Concepción, 1 de octubre de 2015.

RAMOS PAZOS, René. "Del Precario", Revista de Derecho Universidad de Concepción, n 180, año LIV (Jul-Dic, 1986), Concepción.

ROSTION CASAS, Ignacio, El precario en la jurisprudencia chilena (1996 a 2013), Legal Publishing- Thomson Reuters, Santiago, 2014.

\section{Fernando Ruiz Astete}

Abogado, Máster en Informática y Derecho por la Universidad Complutense de Madrid, Profesor de Derecho Civil en Universidad UNIACC. Autor de artículos en materias de Derecho Civil y Derecho Informático. El presente artículo es el fruto de investigación realizada bajo el auspicio de una beca CONICYT (2012) para estudios doctorales cursados en la Facultad de Derecho de la Universidad de Los Andes, Santiago, Chile. Email: fernandoruizastete@gmail.com. 